\title{
Remote sensing of land use/cover changes and its effect on wind erosion potential in Southern Iran
}

Mahrooz Rezaei, Abdolmajid Sameni, Seyed Rashid Fallah Shamsi, Harm Bartholomeus

Wind erosion is a complex process influenced by different factors. Most of these factors are stable over time, but land use/cover and land management practices are changing gradually. Therefore, this research investigates the impact of changing land use/cover and land management on wind erosion potential in southern Iran. We used a remote sensing data (Landsat ETM + and Landsat 8 imagery of 2004 and 2013) for land use/cover mapping and employed the Iran Research Institute of Forest and Rangeland (IRIFR) method to estimate changes in wind erosion potential. For an optimal mapping, the performance of different classification algorithms and input layers was tested. The amount of changes in wind erosion and land use/cover were quantified using cross-tabulation between the two years. To discriminate land use/cover related to wind erosion, the best results were obtained by combining the original spectral bands with synthetic bands and using Maximum Likelihood classification algorithm (Kappa Coefficient of 0.8 and 0.9 for Landsat ETM+ and Landsat 8, respectively). The IRIFR modelling results indicate that the wind erosion potential has increased over the last decade. Area with a very high sediment yield potential have increased, whereas the area with a low, medium, and high sediment yield potential decreased. The area with a very low sediment yield potential have remained constant. When comparing the change in erosion potential with land use/cover change, it is evident that soil erosion potential has increased mostly in accordance with the increase of the area of agricultural practices. The conversion of rangeland to agricultural land was a major land use change which lead to more agricultural practices and associated soil loss. Moreover, results indicate an increase in sandification in the study area which is also a clear evidence of increasing in soil erosion. 


\title{
Remote Sensing of Land Use/Cover Changes and its Effect on Wind Erosion Potential in Southern Iran
}

\author{
Mahrooz Rezaei a ${ }^{*}$, Abdolmajid Sameni a , Seyed Rashid Fallah Shamsi ${ }^{\text {b}}$, Harm \\ Bartholomeus ${ }^{\mathrm{c}}$ \\ a Department of Soil Science, College of Agriculture, Shiraz University, Shiraz, Iran \\ ${ }^{b}$ Department of Natural Resources engineering and Environmental Sciences, College of \\ Agriculture, Shiraz University, Shiraz, Iran \\ ${ }^{c}$ Laboratory for Geo-Information and Remote Sensing, Wageningen University, \\ Wageningen, The Netherlands
}

\begin{abstract}
Wind erosion is a complex process influenced by different factors. Most of these factors are stable over time, but land use/cover and land management practices are changing gradually. Therefore, this research investigates the impact of changing land use/cover and land management on wind erosion potential in southern Iran. We used a remote sensing data (Landsat ETM+ and Landsat 8 imagery of 2004 and 2013) for land use/cover mapping and employed the Iran Research Institute of Forest and Rangeland (IRIFR) method to estimate changes in wind erosion potential. For an optimal mapping, the performance of different classification algorithms and input layers was tested. The amount of changes in wind erosion and land use/cover were quantified using crosstabulation between the two years. To discriminate land use/cover related to wind erosion, the best results were obtained by combining the original spectral bands with synthetic bands and using Maximum Likelihood classification algorithm (Kappa Coefficient of 0.8 and 0.9 for Landsat ETM+ and Landsat 8, respectively). The IRIFR modelling results indicate that the wind erosion potential has increased over the last decade. Area with a very high sediment yield potential have increased, whereas the area with a low, medium, and high sediment yield potential decreased. The area with a very low sediment yield potential have remained constant. When comparing the change in erosion potential with land use/cover change, it is evident that soil erosion potential has increased mostly in accordance with the increase of the area of agricultural practices. The conversion of rangeland to agricultural land was a major land use change which lead to more agricultural practices and associated soil loss. Moreover, results indicate an increase in sandification in the study area which is also a clear evidence of increasing in soil erosion.
\end{abstract}

\section{Introduction}

Wind erosion is a key problem in arid regions as a component of land degradation, which is not only closely related to geo-ecological factors but also to land use/cover changes and land management practices. Wind action in erosion, transport and subsequently deposition of fine particles, has been recognized as an important environmental problem (Goossens and Riksen 2004). Two-thirds of Iran is located in an arid and semi-arid zone and more than half of the Iranian 
41

42

43

44

45

46

47

48

49

50

51

52

53

54

55

56

57

58

59

60

61

62

63

64

65

66

67

68

69

70

71

72

73

74

75

76

77

78

79

80

81

82

83

provinces are suffering from critical wind erosion (Amiraslani and Dragovich 2011; Hui et al. 2015).

Mensuration of wind erosion is not only important to understand wind erosion itself, but also an important scientific step in efforts to reverse the process of desertification (Yue et al. 2015). However, due to the complex inter-action of human-environment factors and wind erosion, it is difficult to be monitored and assessed. In such a context, erosion models can help to improve prediction and forecasting.

Over the past decades, several models have been developed to describe and estimate wind erosion potential, like the wind erosion equation (WEQ) (Wooodruff and Siddoway 1965), Texas tech erosion analysis model (TEAM) (Gregory et al. 2004), and the wind erosion prediction system (WEPS) (Hagen 1995). These models need a variety of input data which limits their application in regions where this is sparsely available. Further, they are not optimized for the environmental and climatic conditions of Iran according to the employing factors required. In 1995, the Iranian Research Institute of Forests and Rangelands has developed an experimental model of wind erosion, named IRIFR (Ahmadi 1998). IRIFR considers the specific ecological conditions of this area, and can be used to estimate the potential wind erosion in central and southern Iran. The accuracy of the IRIFR model results has been assessed by field measurements using sediment traps (Ahmadi 1998).

Land use/cover change is one of the most sensitive indices of interactions between human activities and natural environment (Minwer Alkharabsheh et al. 2013). So, in recent years, a number of studies have been carried out to estimate effects of land use/cover change on water erosion (Martinez-Casasnovas et al. 2000; Szilassi et al. 2006; Cebecauer and Hofierka 2008; Garcia-Ruiz 2010; Wijitkosum 2012; Minwer Alkharabsheh et al. 2013). All studies indicated a strong impact of land use/cover changes on water erosion and sediment transport rates. However, there are limited studies that investigate the influence of land use/cover changes on wind erosion.

Wind erosion is a key process in land degradation, but has not been studied well in relation with land use and associated land cover changes (Li et al. 2014). Soil physical and chemical characteristics, roughness, and land management practices are factors affecting erosion rates. Although the fundamental mechanism of wind erosion is the same for both rangelands and croplands (Webb and Strong 2011) these factors vary greatly between different land use/covers such as croplands and rangelands.

Facing vast areas of rapid changes, encouraged researchers to employ remote sensing techniques for spatially continuous and fast change detection of land use/cover. For decades, remote sensing has been extensively used for better understanding of land surface characteristics, dynamics and monitoring land use/cover changes (Bartholome and Belward 2005; Gong et al. 2013). Multispectral satellite data have proven to be a precious resource for monitoring land use/cover changes. Among the available multi-spectral imaging systems, the Landsat satellites have been widely used to derive information on land use/cover changes (Gumma et al. 2011; Gong et al. 2013, Karnieli et al. 2014).

The value of remote sensing data is enhanced through skilled interpretation, in conjunction with conventionally mapped information and ground-truthing (Okin et al. 2004). However, due to the unpredictability of wind erosion events and often ephemeral nature of aftermath (Clark et al. 2010), it is generally difficult to assess wind erosion directly from remotely-sensed imageries. So, the 
84

85

86

87

88

89

90

91

92

93

94

95

96

97

98

99

100

101

102

103

104

main objective of this study is to assess the effect of land use/cover changes and land management practices on wind erosion potential during the previous decade in the southern Iran.

\section{Materials and methods}

\subsection{Study Area}

The study area is located in the Fars province, in the southern part of Iran, (from $28^{\circ} 07^{\prime} 15^{\prime \prime}$ to $28^{\circ} 13^{\prime} 07^{\prime \prime} \mathrm{N}$ and $52^{\circ} 07^{\prime} 36^{\prime \prime}$ to $52^{\circ} 23^{\prime} 55^{\prime \prime} \mathrm{E}$, covering an area of $17260 \mathrm{ha}$ ), which is considered as the most critical wind erosion area of the province (Figure 1). The study area is located in the Zagros geological zone, including Mishan, Aghajari, Bakhtiyari formations and Quaternary deposits. Soil of the study area is calcareous with Sandy loam and Loam texture.

The average altitude of the area is $211.5 \mathrm{~m}$ above sea level and the average slope is $0.84 \%$. Mean annual maximum and minimum temperatures are $34^{\circ} \mathrm{C}$ and $17^{\circ} \mathrm{C}$ respectively, with an average of $25.5^{\circ} \mathrm{C}$. The area is facing a $190 \mathrm{~mm}$ average annual precipitation and $1927 \mathrm{~mm}$ of average annual evapotranspiration (NRWMO 2005).

Soil temperature and moisture regime are hyper-thermic and aridic, respectively. The south western direction wind is the prevalent in the study area. The mean annual wind speed at 2 and 10 $\mathrm{m}$ above the soil surface are 4.07 and $5.18 \mathrm{~m} . \mathrm{s}^{-1}$ respectively. Wind erosion and dust storms are severe problems for the local inhabitants.

Rangelands and croplands are the most important land use/covers and land management practices in the region. The dominant plant species are Salsola sp., Stipa capensis, Prosopis juliflora, Atriplex canescens and Haloxylon sp. (NRWMO 2005).

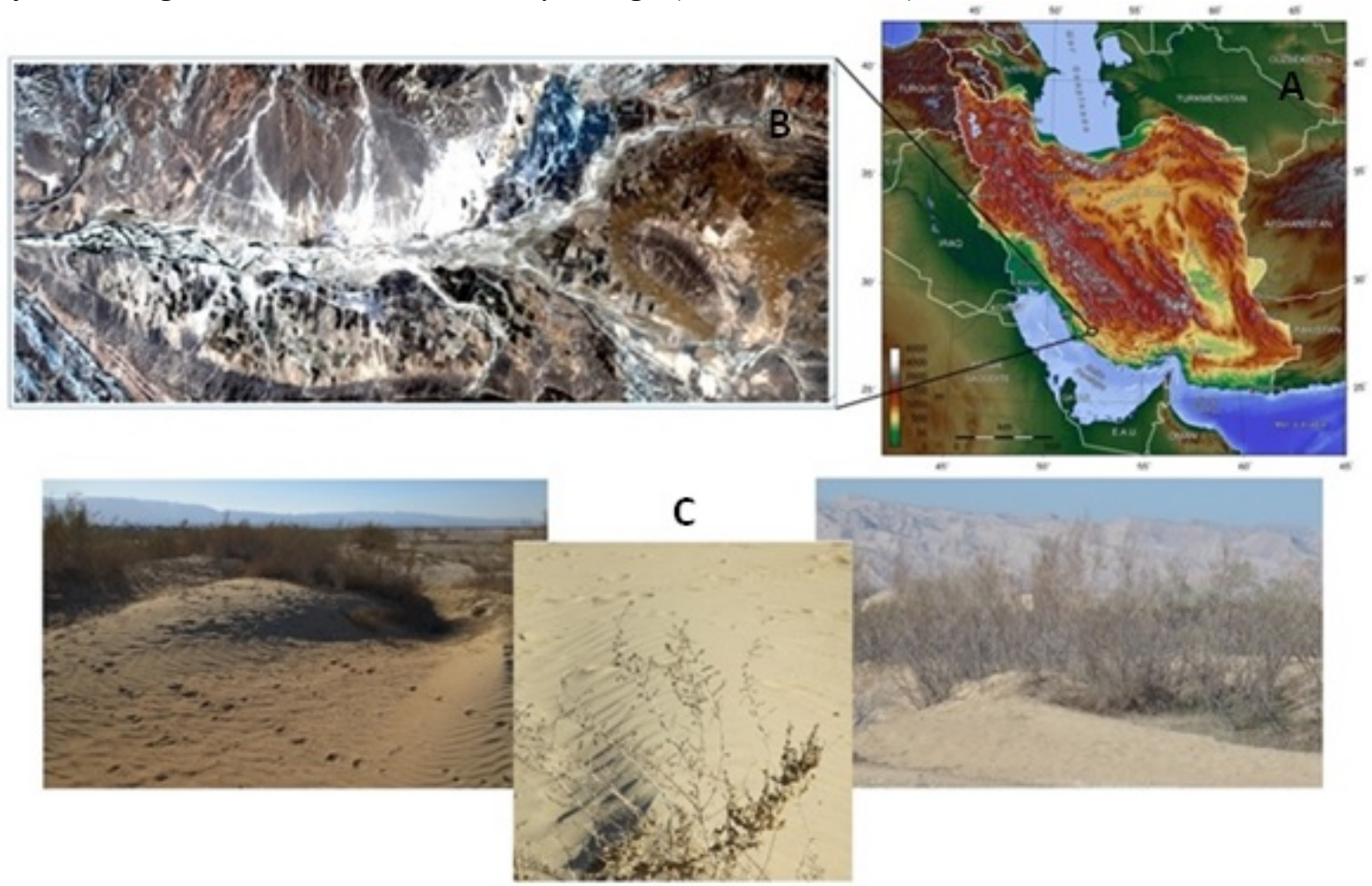

Figure 1. Overview map (A), with the study area indicated and a true color composite of the 2013 Landsat 8 satellite image (B). Evidences of wind erosion in the study area (C). 


\subsection{Assessing Potential of Wind Erosion}

To choose a model to assess the potential wind erosion, data availability and costs have been taken into account. Therefore, the IRIFR model has been chosen due to its suitability for the ecological condition of Iran, data availability and running costs. IRIFR has two versions, developed for two types of landscape: IRIFR1 for non-arable and IRIFR2 for agricultural landscape.

Both IRIFR1 and IRIFR2, like the Pacific Southwest Interagency Committee (PSIAC) model for water erosion, are based on scoring 9 participating factors in the wind erosion process. These factors for IRIFR1 are: lithology, land form, wind velocity, soil and its surface cover, vegetation cover density, signs of soil surface erosion, soil moisture, soil type and distribution of aeolian deposits, land use and land management. The factors for IRIFR2 are: soil (sediment) texture, topography, wind velocity, soil roughness, crust and compressive stress of the soil, soil moisture and irrigation status, soluble salts in soil and irrigation water, vegetation cover or residual density, and cropland management.

These factors are scored according to their effects on sediment yield in a wind erosion process, shown for IRIFR1 and IRIFR2 in Table 1 and Table 2, respectively (Ahmadi 1998). Range of scores in these tables guide the expert to give a score to each factor in each working unit. These ranges were introduced in IRIFR models according to several field studies in different parts of Iran and are based on experts' field knowledge, which was registered through questionnaires. The higher the score in each range the more potential for wind erosion. To produce a map of wind erosion potential based on the IRIFR model, it is necessary to define land units (LU), by overlaying geomorphological and land use/cover thematic maps as the first step. Then, in each LU, the factors were scored according to table 1 and table 2.

Table 1. Scoring the factors for IRIFR1.

\begin{tabular}{lll}
\hline No. & Factors & Range of scores \\
\hline $\mathbf{1}$ & Lithology & $0-10$ \\
$\mathbf{2}$ & Land form (topography) & $0-10$ \\
$\mathbf{3}$ & Wind Velocity & $0-20$ \\
$\mathbf{4}$ & Soil surface cover & $-5-15$ \\
$\mathbf{5}$ & Vegetation cover density & $-5-15$ \\
$\mathbf{6}$ & Signs of soil surface erosion & $0-20$ \\
$\mathbf{7}$ & Soil moisture & $-5-10$ \\
$\mathbf{8}$ & Type and distribution of wind deposits & $0-10$ \\
$\mathbf{9}$ & Land use and land management & $-5-15$ \\
\hline
\end{tabular}

Table 2. Scoring the factors for IRIFR2.

\begin{tabular}{lll}
\hline No. & Factors & Range of scores \\
\hline $\mathbf{1}$ & Soil or sediment texture & $0-10$ \\
$\mathbf{2}$ & Topography & $0-10$ \\
$\mathbf{3}$ & Wind Velocity & $0-20$ \\
$\mathbf{4}$ & Soil roughness & $-5-15$ \\
$\mathbf{5}$ & Crust and compressive stress of the soil & $0-20$ \\
$\mathbf{6}$ & Soil moisture and irrigation status & $-5-15$ \\
$\mathbf{7}$ & Soluble salts in soil and irrigation water & $0-10$ \\
$\mathbf{8}$ & Vegetation cover or residual density & $-5-15$ \\
$\mathbf{9}$ & Cropland management & $-5-15$ \\
\hline
\end{tabular}


The summation of the scores presents the wind erosion potential in the land unit. Finally, sedimentation yield is estimated using equation 1 , in which $\mathrm{Q}_{\mathrm{s}}$ is the total sediment yield in Tons $\mathrm{km}^{-2} \mathrm{y}^{-1}$ and $\mathrm{R}$ is the summation of the 9 participating factors in the models.

$$
\left.\mathrm{Q}_{\mathrm{s}}=41 \mathrm{e}^{0.05 \mathrm{R}} \quad \text { (Equation } 1\right)
$$

Table 3. Classes of wind erosion potential and estimated sedimentation potential for IRIFR1 and IRIFR2.

\begin{tabular}{llll}
\hline Erosion class & Rate of Erosion & Sum of scores & $\begin{array}{l}\text { Sedimentation potential } \\
\left(\mathbf{T o n} \mathbf{h a}^{-\mathbf{1}} \mathbf{y}^{\mathbf{- 1}} \mathbf{)}\right.\end{array}$ \\
\hline I & Very low & Less than 25 & Less than 2.5 \\
II & Low & $25-50$ & $2.5-5$ \\
III & Medium & $50-75$ & $5-15$ \\
IV & High & $75-100$ & $15-60$ \\
V & Very high & More than 100 & More than 60 \\
\hline
\end{tabular}

As shown in Table 1 and Table 2, the most variable factor for both IRIFR1 \& IRIFR2 is land use/cover and, consequently, land management practices. To predict any further change in potential of the study area for wind erosion, we considered change detection of land use/cover pattern and land management as the key factor of the models. To evaluate land use/cover a land management practices over a decade a variety of remote sensing techniques have been employed on Landsat-ETM+ and Landsat-8 images, of 2004 and 2013, respectively.

\subsection{Land Use/Cover Mapping}

\subsubsection{Image Data}

To assess the land use/cover Landsat L1T satellite images acquired on June 292004 (Landsat Enhanced Thematic Mapper Plus (ETM+)) and acquired on June 30 2013, (Landsat 8 Operational Land Imager (OLI) and Thermal Infrared Sensor (TIRS)), were downloaded from the USGS archives (http://earthexplorer.usgs.gov/).

\subsubsection{Image Pre-processing}

The downloaded images were geometrically corrected already, but pre-processing had to be done to ensure radiometric consistency between the images (Koutsias and Pleniou 2015). Therefore, a one-step radiometric correction using the dark-object subtraction method has been employed. This method is used to reduce the haze component in imagery caused by additive scattering from remote sensing data (Chavez Jr 1988). Using the dark-object subtraction method any value above zero in an area of known zero reflectance, such as deep water, represents an overall increase in values across the image and can be subtracted from all values in the corresponding spectral bands. Besides, regarding the SLC (Scan Line Corrector)-off problem of Landsat 7 images, Gap-Fill add-on in Envi software was used for filling the gaps.

Subsequently, histogram matching has been done between the two images. Digital values were extracted in the place of fifty random pixels over both image original bands before and after 
170 histogram matching. A paired sample T-test statistical analysis $(\mathrm{p}<0.05)$ showed that the histogram

171

172

173

174

175

176

177

178

179

180

181

182

183

184

185

186

187

188

189

190

191

192

193

194

195

196

197

198

199

200

201

202

203

204

205

206

207

208

209

210

211

212

213

matching was effective and has significantly changed the sampled digital values.

\subsubsection{Thematic Classes and Training Sampling}

According to the variations in land use/cover spectral behavior across the study area, it was difficult to define training samples representing thematic classes in a supervised classification procedure. Therefore, the selection of adequate and suitable training samples required an in-depth knowledge of the study area, which was achieved through an intensive field work and direct observation. 127 points covering 12 land use/cover classes was collected using a handset global positioning system (GPS). The points were chosen in such a way that they adequately represented the variability of land use/cover spectral behavior in the study area. In addition, because of internal variability of certain thematic classes like agriculture, it was necessary to select some training samples for its subclasses. Residential areas were masked from the images.

Quality training samples were identified for the thematic classes, including rangeland, agricultural land with four subclasses, bare land, insusceptible areas with two subclasses, fan, residential area and others. Land use/covers related to wind erosion process such as Nebka and sand sheets were also included in the thematic classes, presenting wind erosion potential in the study area.

\subsubsection{Image Processing and Band Selection}

To investigate which combination of Landsat spectral bands yields the best classification results we analyzed the performance of three different input band combinations for our classification: a) the original spectral bands, b) the first three principal components (PC-3), and c) a combination of original and processed bands based on separability analysis.

For the last input data selection a variety of image processing and enhancement techniques was employed. The processed bands/indices included: band compositing, soil and vegetation indices calculation (VIs given in Table 4), principal component analysis (PCA), band fusion and texture analysis.

Next to calculation of VIs, texture analysis was employed using Variability, Fractal dimension, and Edge analysis methods, to detect areas that can be characterized by some form of repeating pattern on the ground. The edge analysis was done to provide convolution filters to enhance edge patterns in specific directions. Moreover, the prevalent wind direction can be taken into account via this analysis. Moreover, Gram-Schmidt spectral sharpening (Laben and Brower 2000), was performed to provide a higher resolution observation of the surface in a given period. These calculations were done using ENVI 5.1 and IDRISI taiga software.

To select the best combination of original and synthetic bands for final classification a hierarchical selection procedure was done, using the training dataset. At first, highly-correlated bands (correlation coefficient $>0.8$ ) were removed to reduce repetitive information content. For example, the correlation coefficient of SWIR 1 and SWIR 2 was 0.96 , thus only one of them $\left(\mathrm{SWIR}_{1}\right)$ was entered in the classification procedure. Further the main strategy of band selection was to select bands with a maximum separability for land use/cover classification. For this, statistical measures on the separability of signatures over a given set of bands were investigated. Further, the Digital Numbers of bands and calculated indices were plotted as a function of the band sequence producing a signature comparison chart (mean values) for the thematic classes using the 
214 SIGCOMP module in IDRISI. The bands in which the greatest separability among all classes 215 occurred, were selected as optimal ones for recognition of these particular classes. For example 216 among the soil and VIs, most of the classes were different from one another when looking at the 217 WDVI, SI, YSI, LI indices, thus the other indices were removed from the classification procedure. 218 Finally, the Transformed Divergence (TD) was calculated to assess the spectral separability of the 219 training areas as shown in Table 6 (Richards and Jia 2006). In TD, we refer to 0 for the complete 220 overlap between class pair signatures and to 2 for the total separation of the classes. The final 221 training areas were selected by maximizing the separability metrics.

222

223

224

Table 4. Soil and Vegetation Indices (VIs).

\begin{tabular}{|c|c|c|c|}
\hline No. & Index & Equation & Reference \\
\hline 1 & $\begin{array}{l}\text { normalized difference } \\
\text { vegetation index }\end{array}$ & $\mathrm{NDVI}=(\mathrm{NIR}-\mathrm{RED}) /(\mathrm{NIR}+\mathrm{RED})$ & Rouse et al. 1974 \\
\hline 2 & $\begin{array}{l}\text { transformed vegetation } \\
\text { index }\end{array}$ & $\mathrm{TVI}=[(\mathrm{NIR}-\mathrm{RED} / \mathrm{NIR}+\mathrm{RED})+0.5]^{0.5}$ & Deering et al. 1975 \\
\hline 3 & $\begin{array}{l}\text { corrected transformed } \\
\text { vegetation index }\end{array}$ & $\begin{array}{l}\mathrm{CTVI}= \\
{\left[(\mathrm{NDVI}+0.5) / \mathrm{ABS}^{*}(\mathrm{NDVI}+0.5)\right] \cdot[\mathrm{ABS}(\mathrm{NDVI}+0.5)]} \\
0.5\end{array}$ & $\begin{array}{l}\text { Perry and Lautenschlager } \\
1984\end{array}$ \\
\hline 4 & $\begin{array}{l}\text { Thiam's transformed } \\
\text { vegetation index }\end{array}$ & $\mathrm{TTVI}=[\mathrm{ABS}(\mathrm{NDVI}+0.5)]^{0.5}$ & Thiam 1997 \\
\hline 5 & ratio vegetation index & $\mathrm{RVI}=\mathrm{RED} / \mathrm{NIR}$ & $\begin{array}{l}\text { Richardson and Wiegand } \\
1977\end{array}$ \\
\hline 6 & $\begin{array}{l}\text { normalized ratio } \\
\text { vegetation index }\end{array}$ & $\mathrm{NRVI}=(\mathrm{RVI}-1) /(\mathrm{RVI}+1)$ & Baret and Guyot 1991 \\
\hline 7 & $\begin{array}{l}\text { soil adjusted } \\
\text { vegetation index }\end{array}$ & $\mathrm{SAVI}=(\mathrm{NIR}-\mathrm{RED}) /\left(\mathrm{NIR}+\mathrm{RED}+\mathrm{L}^{*}\right) \cdot(1+\mathrm{L})$ & Huete 1988 \\
\hline 8 & $\begin{array}{l}\text { transformed soil } \\
\text { adjusted vegetation } \\
\text { index }\end{array}$ & TSAVI $=\left[a^{*}\left(N I R-a \cdot R E D-b^{*}\right)\right] /($ RED $+a \cdot N I R-a . b)$ & Baret et al. 1989 \\
\hline 9 & $\begin{array}{l}\text { modified soil adjusted } \\
\text { vegetation index }\end{array}$ & MSAVI $=[(\mathrm{NIR}-\mathrm{RED}) /(\mathrm{NIR}+\mathrm{RED}+\mathrm{L})] \cdot(1+\mathrm{L})$ & Qi et al. 1994 \\
\hline 10 & $\begin{array}{l}\text { weighted difference } \\
\text { vegetation index }\end{array}$ & WDVI= NIR-a.RED & $\begin{array}{l}\text { Richardson and Wiegand } \\
1977\end{array}$ \\
\hline 11 & $\begin{array}{l}\text { difference vegetation } \\
\text { index }\end{array}$ & $\mathrm{DVI}=\mathrm{a} \cdot \mathrm{NIR}-\mathrm{RED}$ & $\begin{array}{l}\text { Richardson and Wiegand } \\
1977\end{array}$ \\
\hline 12 & $\begin{array}{l}\text { perpendicular } \\
\text { vegetation index }\end{array}$ & $\mathrm{PVI}=\left[\left(\mathrm{RED}_{\text {soil }}-\mathrm{RED}_{\mathrm{veg}}\right)^{2}+\left(\mathrm{NIRs}_{\mathrm{oil}}-\mathrm{NIR}_{\mathrm{veg}}\right)^{2}\right]^{0.5}$ & $\begin{array}{l}\text { Richardson and Wiegand } \\
1977\end{array}$ \\
\hline 13 & $\begin{array}{l}\text { normalized difference } \\
\text { water index }\end{array}$ & NDWI= (NIR-SWIR)/(NIR+SWIR) & Cheng et al. 2008 \\
\hline 14 & $\begin{array}{l}\text { normalized difference } \\
\text { salinity index }\end{array}$ & $\mathrm{NDSI}=(\mathrm{RED}-\mathrm{NIR}) /(\mathrm{RED}+\mathrm{NIR})$ & Khan et al. 2001 \\
\hline 15 & Yazd salinity index & $\mathrm{YSI}=(\mathrm{RED}-\mathrm{BLUE}) /(\mathrm{RED}+\mathrm{BLUE})$ & Dashtekian et al. 2008 \\
\hline 16 & salinity index & $\mathrm{SI}=(\mathrm{SWIR} 1-\mathrm{SWIR} 2) /(\mathrm{SWIR} 1+\mathrm{SWIR} 2)$ & Khaier 2003 \\
\hline 17 & limestone index & $\mathrm{LI}=\left(\mathrm{SWIR} 2^{2}-\mathrm{NIR}^{2}\right) /\left(\mathrm{SWIR} 2^{2}+\mathrm{NIR}^{2}\right)$ & Mokhtari et al. 2005 \\
\hline 18 & brightness index & $\mathrm{BI}=\left(\mathrm{RED}^{2}+\mathrm{NIR}^{2}\right)^{0.5}$ & Khan et al. 2001 \\
\hline
\end{tabular}


231

232

233

234

235

236

237

238

239

240

241

242

243

244

245

246

247

248

249

250

251

252

253

254

255

256

257

258

259

260

261

262

PCA was used to remove redundant information and was applied to solar-reflective spectral bands. The first three components described almost all the variance (Table 5).

Table 5. Eigenvalues off the different eigen vectors after PCA for landsat 7 and 8, band 1 to 7 .

\begin{tabular}{ccc}
\hline Eigen vector & \multicolumn{2}{c}{ Variance (\%) } \\
\cline { 2 - 3 } & Landsat 7 & Landsat 8 \\
\hline $\mathbf{1}$ & 73.43 & 82.38 \\
$\mathbf{2}$ & 23.15 & 13.09 \\
$\mathbf{3}$ & 2.34 & 3.74 \\
$\mathbf{4}$ & 0.84 & 0.75 \\
$\mathbf{5}$ & 0.16 & 0.04 \\
$\mathbf{6}$ & 0.08 & 0.002 \\
$\mathbf{7}$ & - & 0.0003 \\
\hline
\end{tabular}

\subsubsection{Image Classification Procedure}

An integrated field survey and satellite remote sensing analysis was employed based on unsupervised and supervised image classification procedures (Richards and Jia 2006) to produce an accurate map of land use/cover changes and land management practices for the study area.

The classification scheme includes a preliminary analysis on both Landsat images. The same type of analysis for the two different Landsat scenes was carried out by testing the same combinations of classifiers with input data and training datasets. After the input bands were selected according to the method described in section 2.3.4, different supervised classification algorithms were tested, including Parallelepiped (PPD), Minimum Distance Classifier (MD), Mahalanobis Distance (MHD), and Maximum Likelihood Classifier (ML). It was found that Maximum Likelihood yielded the best results (See Table 7). Therefore, land use/cover map for 2004 and 2013 were produced using Maximum Likelihood (ML) rule of classification, shown in Figure 3 and 4. In order to discriminate the river basin from bare land outside the river, river basin was masked and reclassified for further analysis. Thus, unclassified class in further tables are showing the bare land outside the river.

\subsubsection{Accuracy Assessment}

The Overall Accuracy (OA) and Cohen's Kappa coefficient (K), derived from the error matrix were used for the accuracy assessment of the final maps (Congalton and Green 1999). To generate a ground truth dataset, 94 locations were selected using random sampling, which were then visited to describe the land-cover type through field surveys. Next to this, the locations were controlled through visual interpretation of very high spatial resolution images that are available online on the Google Earth website.

\subsection{Change Detection}

Change analysis was performed by calculating cross-tabulation statistics derived from paircomparison of classification results for 2004 and 2013. In addition, the analysis of the causes associated with the changes on soil losses was performed by cross-tabulation of the soil loss map and the map of land use/cover changes. 


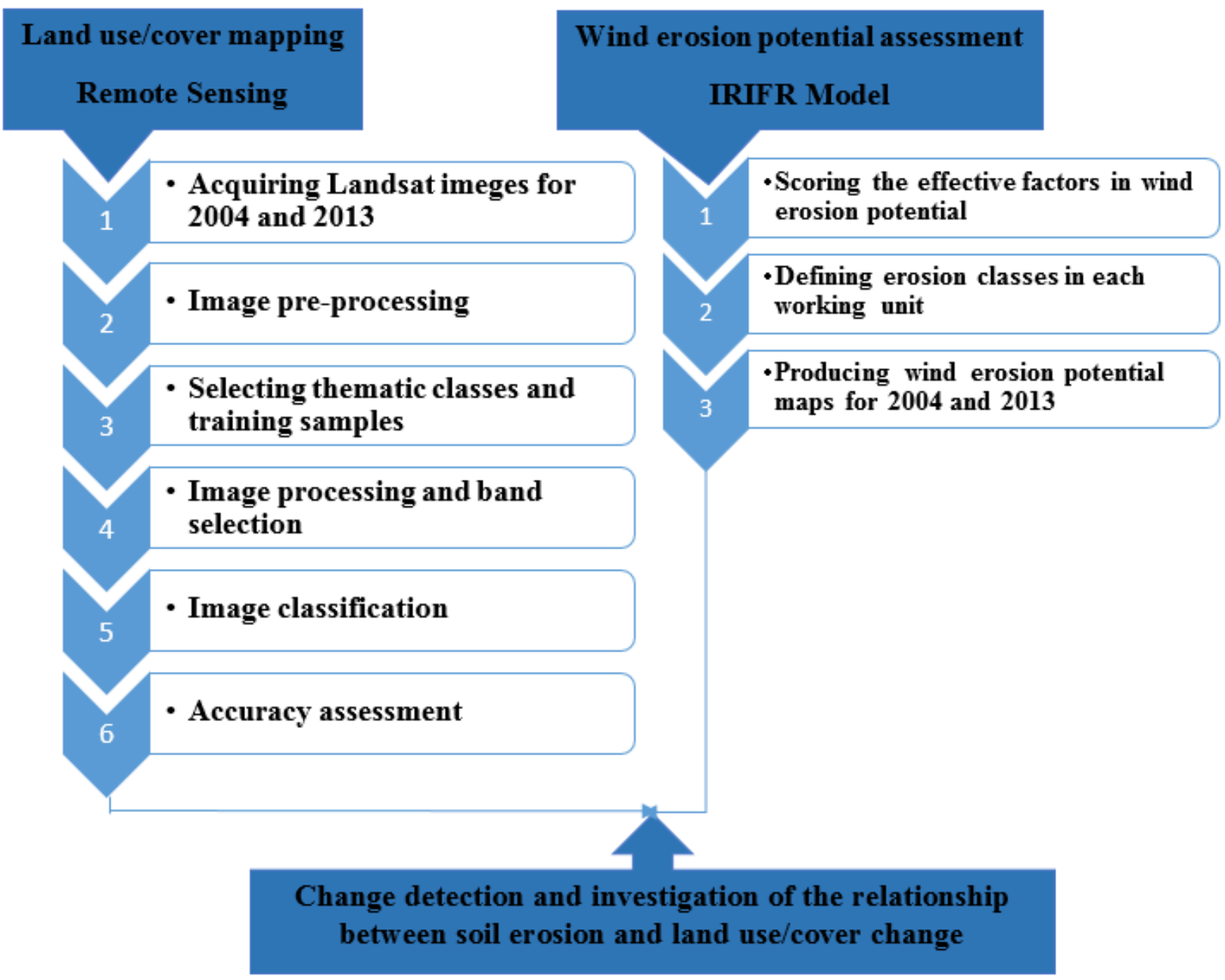

Figure 2. Flowchart of the research. 
Table 6. Transformed Divergence (TD) of the training set for Landsat7-ETM ${ }^{+}$and Landsat8- OLE imagery.

\begin{tabular}{|c|c|c|c|c|c|c|c|c|c|c|c|c|c|c|c|c|c|c|c|c|c|c|c|c|}
\hline \multirow[b]{2}{*}{ Training set } & \multicolumn{2}{|c|}{ Rangeland } & \multicolumn{2}{|c|}{ Sand sheet } & \multicolumn{2}{|c|}{ Nebka } & \multicolumn{2}{|c|}{ Agi.1 } & \multicolumn{2}{|c|}{ Agri. 2} & \multicolumn{2}{|c|}{ Agri.3 } & \multicolumn{2}{|c|}{ Agri.4 } & \multicolumn{2}{|c|}{ Bare land } & \multicolumn{2}{|c|}{ Ins.1 } & \multicolumn{2}{|c|}{ Ins.2 } & \multicolumn{2}{|c|}{ Fan } & \multicolumn{2}{|c|}{ Others } \\
\hline & L7 & $\mathbf{L 8}$ & L7 & L8 & L7 & L8 & L7 & L8 & L7 & L8 & L7 & L8 & L7 & L8 & L7 & L8 & L7 & L8 & L7 & L8 & L7 & $\mathbf{L 8}$ & L7 & L8 \\
\hline Rangeland & & & 2 & 2 & 1.94 & 2 & 2 & 2 & 1.98 & 2 & 1.9 & 2 & 2 & 2 & 2 & 2 & 2 & 2 & 1.89 & 2 & 2 & 2 & 2 & 2 \\
\hline Sand sheet & 2 & 2 & & & 2 & 1.98 & 2 & 2 & 2 & 2 & 1.99 & 2 & 1.98 & 1.9 & 1.96 & 1.99 & 2 & 2 & 2 & 2 & 2 & 2 & 2 & 2 \\
\hline Nebka & 1.94 & 2 & 2 & 1.98 & & & 2 & 2 & 2 & 2 & 1.98 & 2 & 2 & 1.99 & 2 & 2 & 2 & 2 & 2 & 2 & 2 & 2 & 2 & 2 \\
\hline Agri. $1^{*}$ & 2 & 2 & 2 & 2 & 2 & 2 & & & 2 & 2 & 2 & 2 & 1.99 & 2 & 2 & 2 & 2 & 2 & 2 & 2 & 2 & 2 & 1.99 & 2 \\
\hline Agi. 2 & 1.98 & 2 & 2 & 2 & 2 & 2 & 2 & 2 & & & 1.93 & 1.88 & 2 & 2 & 2 & 2 & 2 & 2 & 1.97 & 2 & 2 & 2 & 2 & 2 \\
\hline Agri.3 & 1.9 & 2 & 1.99 & 2 & 1.98 & 2 & 2 & 2 & 1.93 & 1.88 & & & 2 & 1.89 & 1.82 & 1.79 & 2 & 2 & 2 & 2 & 2 & 2 & 1.96 & 1.96 \\
\hline Agri.4 & 2 & 2 & 1.98 & 1.9 & 2 & 1.99 & 1.99 & 2 & 2 & 2 & 2 & 1.89 & & & 1.96 & 1.97 & 2 & 2 & 2 & 2 & 2 & 2 & 2 & 2 \\
\hline Bare land & 2 & 2 & 1.96 & 1.99 & 2 & 2 & 2 & 2 & 2 & 2 & 1.82 & 1.79 & 1.96 & 1.97 & & & 2 & 2 & 2 & 2 & 2 & 2 & 1.99 & 2 \\
\hline Ins. $1^{* *}$ & 2 & 2 & 2 & 2 & 2 & 2 & 2 & 2 & 2 & 2 & 2 & 2 & 2 & 2 & 2 & 2 & & & 2 & 2 & & 2 & 1.98 & 1.99 \\
\hline Ins. 2 & 1.89 & 2 & 2 & 2 & 2 & 2 & 2 & 2 & 1.97 & 2 & 2 & 2 & 2 & 2 & 2 & 2 & 2 & 2 & & & 2 & 2 & 2 & 1.96 \\
\hline Fan & 2 & 2 & 2 & 2 & 2 & 2 & 2 & 2 & 2 & 2 & 2 & 2 & 2 & 2 & 2 & 2 & 2 & 2 & 2 & 2 & & & 2 & 2 \\
\hline Others & 2 & 2 & 2 & 2 & 2 & 2 & 1.99 & 2 & 2 & 2 & 1.96 & 1.96 & 2 & 2 & 1.99 & 2 & 1.98 & 1.99 & 2 & 1.96 & 1.8 & 1.79 & & \\
\hline
\end{tabular}

$273 *$ Agri.1, 2, 3, and 4: Difference is based on land management.

274 ** Ins. 1, 2: Difference is based on the type of soil surface.

275

276

277

278

279

280

281

282

283

284

285

286 
287

288

289

290

291

292

293

294

295

296

297

298

299

300

301

302

303

304

305

306

\section{Results and Discussion}

\subsection{Land use/cover changes from 2004-2013}

The most accurate result was obtained using the selected combination of input data and ML classification algorithm (overall accuracy of $84 \%$ and $90.8 \%$ and Kappa coefficient of 0.8 and 0.9 for Landsat 7 and 8, respectively) for both Landsat images (Table 7). Yousefi et al. (2015) also found that ML algorithm is one of the best algorithms for land use mapping with average of 0.94 Kappa coefficient. According to the correlation and separability metrics, the near infrared (NIR) and short infrared band (SWIR1), the linear saturated thermal infrared band (TIR), the WDVI, SI, YSI, LI indices, and processed bands by edge analysis in the aspect of E-W and SE-NW were finally selected as the best input band combination. Land use/cover maps for 2004 and 2013 are shown in Figure 3 and 4. Land use/cover variability of the study area comprised 12 classes. Table 8 indicates the area of each land use/cover class and its relative change during the period.

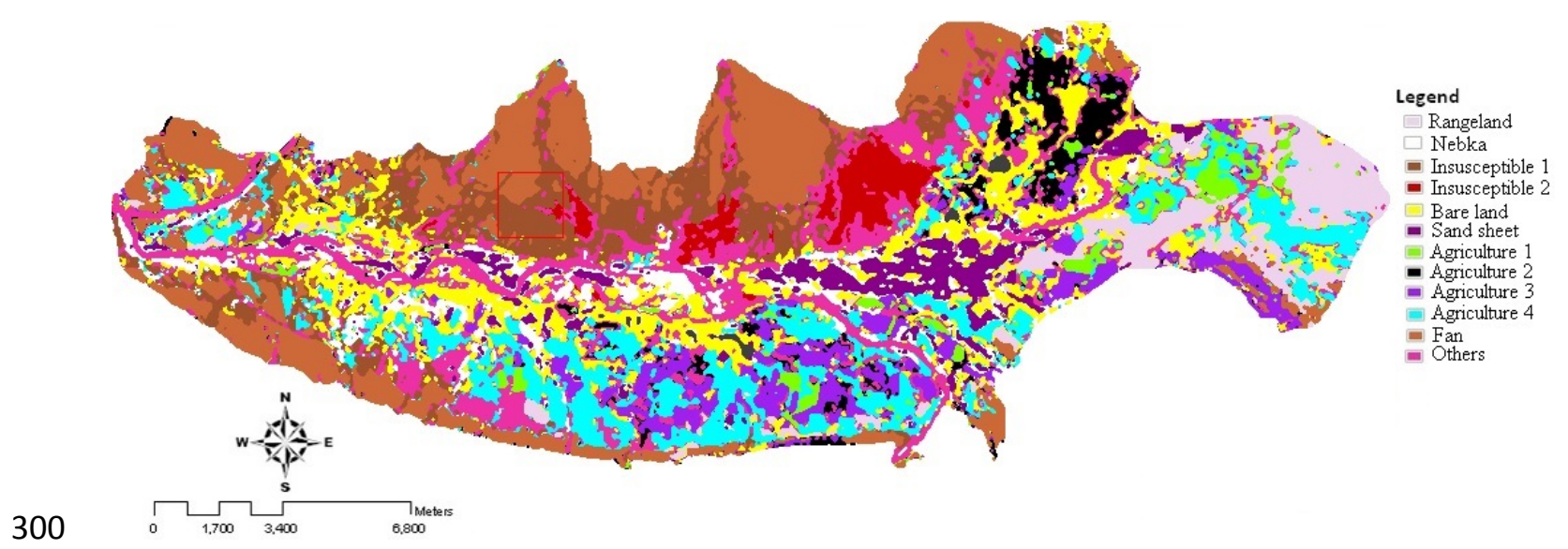

Figure 3. Land use/cover map of 2004, using ML rule.

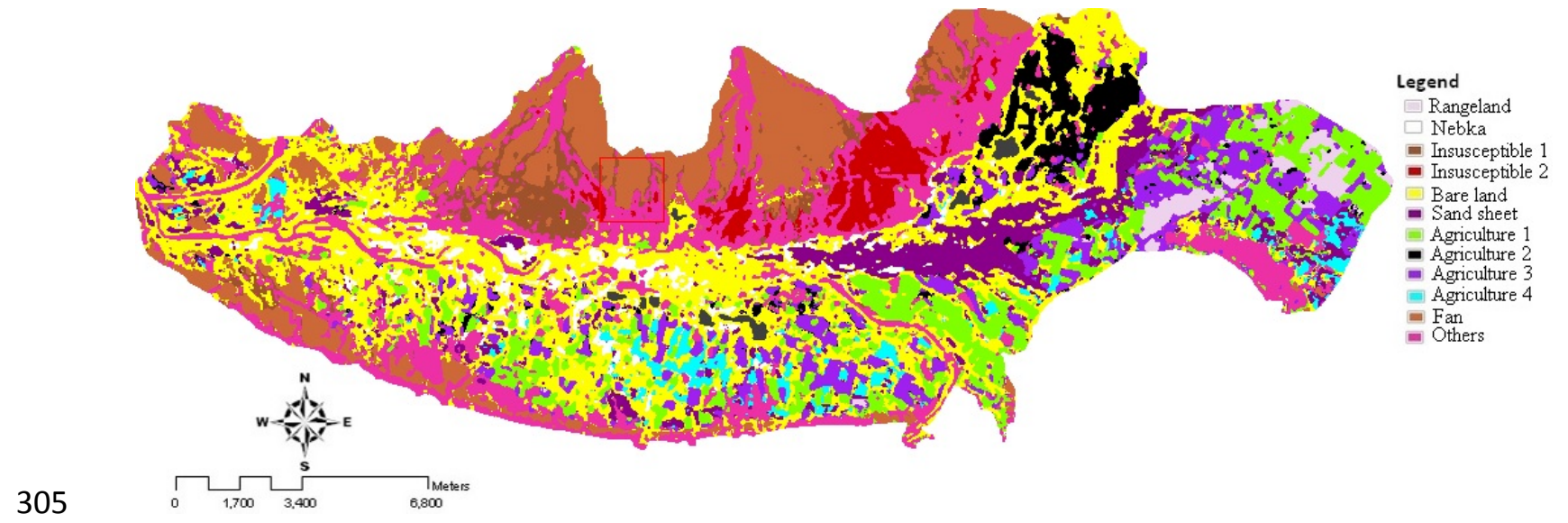

Figure 4. Land use/cover map for 2013, using ML rule. 
307 308

309

310

311

312

313

Table 7. Overall Accuracy and Kappa Coefficient for the results of PPD, MD, MHD, and ML classification algorithms.

\begin{tabular}{c|lcccccccc}
\hline Image & & \multicolumn{4}{c}{ Overall Accuracy } & \multicolumn{4}{c}{ Kappa Coefficient } \\
\cline { 3 - 9 } & \multicolumn{1}{c}{ Algorithm } & PPD & MD & MHD & ML & PPD & MD & MHD & ML \\
\hline Landsat 7 & Spectral bands* & 50 & 56 & 58.4 & 78.3 & 0.43 & 0.47 & 0.47 & 0.67 \\
& PC-3 & 48.2 & 54.3 & 55.4 & 60 & 0.4 & 0.5 & 0.41 & 0.54 \\
& Selected inputs** & 75.6 & 56.5 & 76 & 84 & 0.66 & 0.5 & 0.65 & 0.8 \\
Landsat 8 & Spectral bands & 57.4 & 71.4 & 78.3 & 80.1 & 0.53 & 0.67 & 0.74 & 0.74 \\
& PC-3 & 40 & 71 & 71 & 78 & 0.37 & 0.68 & 0.68 & 0.7 \\
& Sele1cted inputs & 65.2 & 78.6 & 80 & 90.8 & 0.62 & 0.71 & 0.75 & 0.9 \\
\hline
\end{tabular}

* Spectral bands: Original bands of landsat 7 and landsat 8.

** Selected bands: Input band combination selected based on separability metrics.

Table 8. Land use/cover of the study area in 2004 and 2013.

\begin{tabular}{|c|c|c|c|c|}
\hline & \multirow[t]{2}{*}{ Land use/cover } & \multicolumn{2}{|c|}{ Area (ha) } & \multirow{2}{*}{$\begin{array}{c}\text { Relative change } \\
\text { of land use/cover } \\
(\%)\end{array}$} \\
\hline & & 2004 & 2013 & \\
\hline & Rangeland & 1128 & 280 & -75 \\
\hline & Sand sheet & 854 & 1303 & 52 \\
\hline & Nebka & 949 & 504 & -46 \\
\hline \multirow{5}{*}{$\begin{array}{l}\text { Agricultural } \\
\text { Land* }\end{array}$} & 1 & 609 & 1973 & 223 \\
\hline & 2 & 671 & 797 & 18 \\
\hline & 3 & 1019 & 1244 & 22 \\
\hline & 4 & 2078 & 409 & -80 \\
\hline & $\begin{array}{l}\text { Bare Land (River } \\
\text { Basin) }\end{array}$ & 349 & 958 & 174 \\
\hline \multirow{6}{*}{$\begin{array}{c}\text { Insusceptible } \\
\text { areas** }\end{array}$} & 1 & 1383 & 430 & -68 \\
\hline & 2 & 404 & 710 & 75 \\
\hline & Alluvial Fan & 2946 & 1891 & -35 \\
\hline & Residential area & 50 & 96 & 91 \\
\hline & Others & 3372 & 3539 & 4 \\
\hline & Unclassified & 1483 & 3142 & 111 \\
\hline
\end{tabular}

Several significant changes in land use/cover occurred between 2004 and 2013 (Table 9). These 
323

324

325

326

327

328

329

330

331

332

333

334

335

336

337

338

339

340

341

342

343

344

345

346

347

348

349

350

351

Moreover, $10.23 \%$ of these rangelands changed to sand areas in 2013. Low-efficiency irrigation systems combined with an increase in soil loss from arable lands leads to reduction in productivity. This is in line with findings by Minwer Alkharabsheh et al. (2013) who reported the progressive decrease of the agricultural areas and mixed rain-fed areas as the main reason of declining in soil erosion in Jordan.

Sand sheets/bare sands were also facing a change of about 52.62\% from 2004 to 2013, showing an expansion mostly to the southeastern parts. The sandification rate is an important index of land degradation, which involves aeolian erosion, windblown sands, shifting dunes and moving sands toward agricultural and residential areas (Jiang 2002, Karnieli et al. 2014). Nebkas decreased by 46.84 percent in the study area due to a decrease in vegetation cover. Moreover, the Nebkas were found to be unstable during field observations, therefore they have the potential to be blown away by wind and deposited at another location. Bare lands also increased significantly in 2013 compared to 2004. Bare lands or non-vegetation areas have a higher risk of soil erosion by wind than soil with a good vegetation cover. Leh et al. (2013) also reported bare lands as one of the major source of increased erosion in the Ozark Highlands of the USA. In addition, residential areas increased by $91.64 \%$ in the study area between 2004 and 2013. In general, agricultural areas increased in the study area in 2013, and because of traditional cultivation methods in the study area, a short growing season which leads to short periods of soil surface cover, the absence of windbreaks, the wind erosion potential will be increased. Within the year, the difference in acquisition date of the satellite images which were used was just one day. Therefore the changes in vegetation crown cover are probably not related to phenological differences within the growing season. During the long fallow stage, agricultural lands are without vegetation cover and farmers plough their fields several times during the rain events to increase the infiltration of the rainwater which eventually cause an increase in wind erosion potential.

In $2004,2079 \mathrm{~m}^{2}$ of the study area abandoned from agricultural use, which decreased by 80 percent in 2013. The agricultural land use change from abandoned land to arable land had an influence on wind erosion potential. In prior abandoned land, physical soil crusts developed more frequently. Usual mitigation measures by farmers has been tillage operations to reduce crusting, but this increased the potential of wind erosion (Fister and Ries 2009). 
Table 9. Matrix of changes in land use/cover (\%).

\begin{tabular}{|c|c|c|c|c|c|c|c|c|c|c|c|c|c|c|c|c|}
\hline & Rangeland & $\begin{array}{l}\text { Sand } \\
\text { sheet }\end{array}$ & Nebka & Agri.1 & Agri. 2 & Agri.3 & Agri.4 & $\begin{array}{l}\text { Bare } \\
\text { land }\end{array}$ & Ins. 1 & Ins. 2 & Fan & $\begin{array}{l}\text { Residential } \\
\text { area }\end{array}$ & Others & Unclassified & $\begin{array}{c}\text { Class } \\
\text { total }\end{array}$ \\
\hline \multirow{17}{*}{ 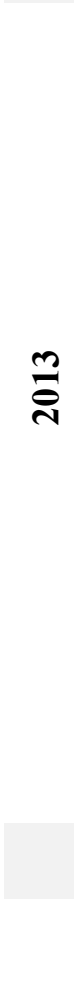 } & Rangeland & 23.81 & 0 & 0 & 4.03 & 0 & 0.12 & 0.42 & 0 & 0 & 0 & 0 & 0 & 0.02 & 0.1 & 100 \\
\hline & Sand sheet & 10.23 & 47.84 & 16.1 & 4.03 & 1.29 & 4.2 & 9.19 & 19.79 & 0.6 & 0 & 0.47 & 0 & 5.12 & 8.09 & 100 \\
\hline & Nebka & 0.09 & 9.07 & 11.57 & 0.49 & 0.24 & 0.65 & 2.09 & 12.94 & 0.1 & 0.29 & 0.02 & 0 & 4.18 & 4.87 & 100 \\
\hline & Agri.1 & 36.92 & 5.71 & 0.62 & 25 & 6.88 & 29.5 & 23 & 1.65 & 1.36 & 0.09 & 1.41 & 0 & 6.8 & 10.05 & 100 \\
\hline & Agri.2 & 1.75 & 0.35 & 0.38 & 12.5 & 46.6 & 3.67 & 2.81 & 0.13 & 0.04 & 0 & 2.29 & 0 & 2.13 & 11.48 & 100 \\
\hline & Agri.3 & 16.53 & 2.61 & 3.33 & 28.6 & 8.9 & 24.5 & 16.8 & 1.03 & 0.28 & 0 & 0.54 & 0 & 1.58 & 6.48 & 100 \\
\hline & Agri.4 & 0.02 & 0.87 & 0.94 & 2.61 & 2.59 & 11.4 & 6.58 & 0 & 0.3 & 0 & 0.6 & 0 & 0.72 & 2.07 & 100 \\
\hline & Bare land & 0.04 & 14.45 & 26.2 & 1.82 & 2.88 & 0.34 & 0.04 & 58.48 & 0.03 & 0.27 & 0 & 0 & 8.82 & 0 & 100 \\
\hline & Ins.1 & 0 & 0.01 & 0.09 & 0.16 & 0 & 0.01 & 0.06 & 0 & 44.8 & 0.09 & 4.69 & 0 & 1.02 & 0.02 & 100 \\
\hline & Ins. 2 & 0 & 0 & 0.24 & 0.13 & 0.03 & 0 & 0.28 & 0 & 6.56 & 87.9 & 0.49 & 0 & 7.1 & 0.04 & 100 \\
\hline & Fan & 0.33 & 0.02 & 0.095 & 0.22 & 0.03 & 0.04 & 0.04 & 0 & 15.2 & 0.2 & 59.58 & 0 & 0.48 & 0.02 & 100 \\
\hline & $\begin{array}{l}\text { Residential } \\
\text { area }\end{array}$ & 0 & 0.42 & 0.664 & 0.01 & 0.08 & 0 & 0.02 & 0 & 0 & 0 & 0 & 100 & 0.1 & 2.17 & 100 \\
\hline & Others & 2.61 & 3.97 & 13.84 & 5.57 & 6.43 & 2.34 & 6.47 & 5.98 & 25.9 & 10.7 & 26.6 & 0 & 41.72 & 8.45 & 100 \\
\hline & Unclassified & 7.67 & 14.68 & 25.93 & 14.9 & 24.1 & 23.2 & 32.1 & 0 & 4.94 & 0.42 & 3.31 & 0 & 20.21 & 46.16 & 100 \\
\hline & Class total & 100 & 100 & 100 & 100 & 100 & 100 & 100 & 100 & 100 & 100 & 100 & 100 & 100 & 100 & \\
\hline & Class changes & 76.19 & 52.16 & 88.43 & 75 & 53.4 & 75.5 & 93.4 & 41.52 & 55.2 & 12.1 & 40.42 & $\mathbf{0}$ & 58.28 & 53.84 & \\
\hline & $\begin{array}{c}\text { Image } \\
\text { difference }\end{array}$ & -75.13 & 52.62 & -46.84 & 224 & 18.8 & 22.2 & -80 & 174.59 & -68.9 & 75.8 & -35.8 & 91.64 & 4.93 & 111.86 & \\
\hline
\end{tabular}


359

360

361

362

363

364

365

366

367

368

369

370

371

372

373

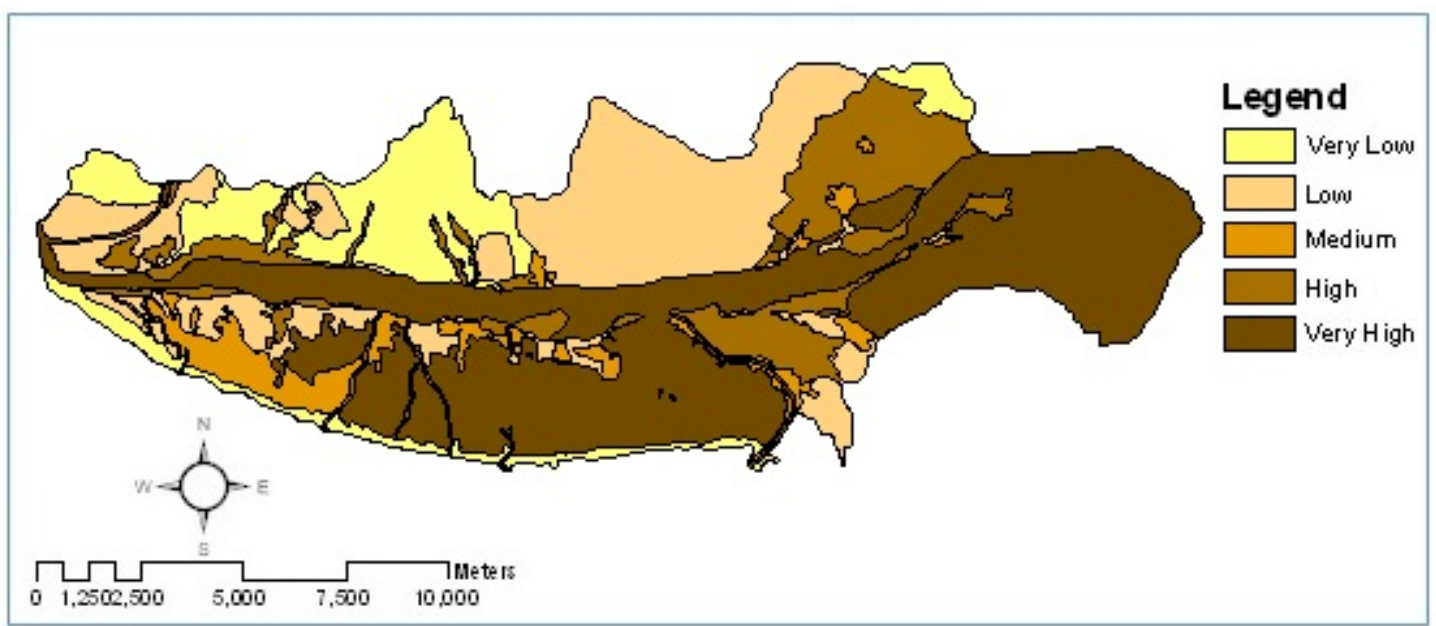

Figure 6. Wind erosion potential map of the study area using IRIFR models in 2013. 


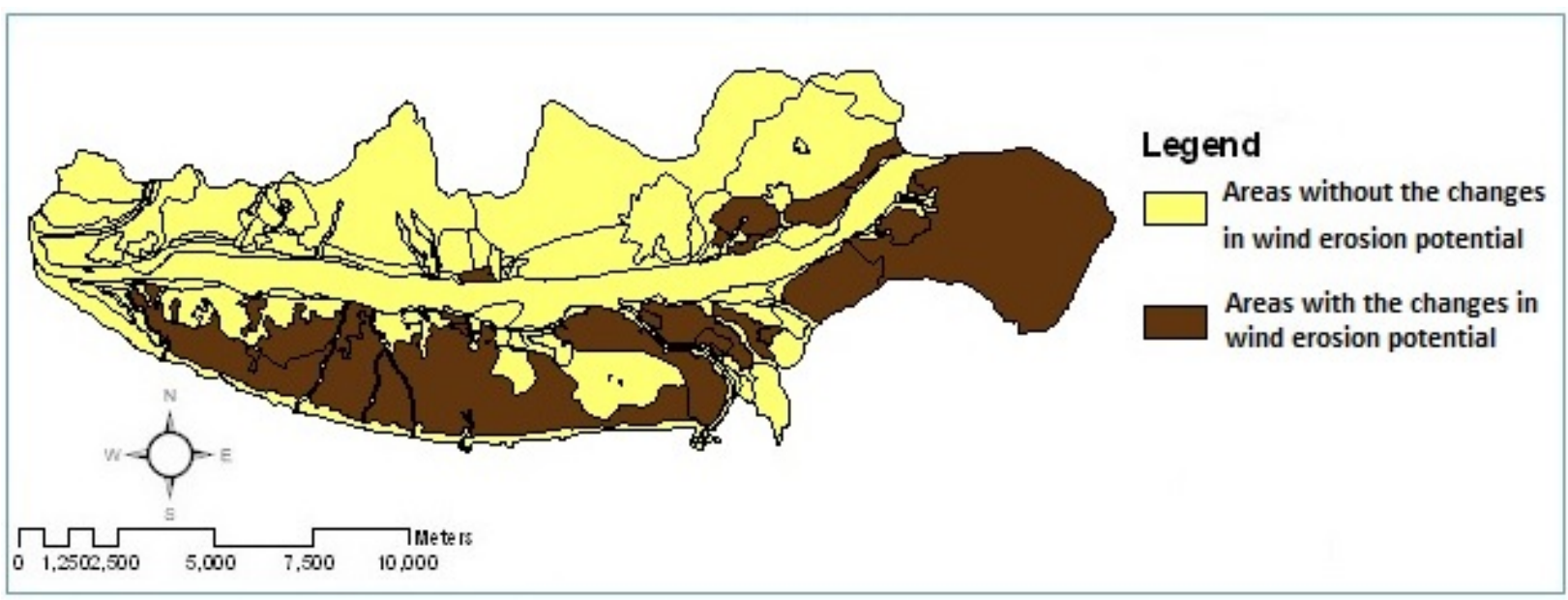

Figure 7. The change of wind erosion potential between 2004 and 2013.

Table 3 and Figure $5 \&$ Figure 6, indicate that the potential of sediment yield varies from 0.83 tonha $\mathrm{y}^{-1} \mathrm{y}^{-1}$ to 272.71 ton $\mathrm{ha}^{-1} \mathrm{y}^{-1}$ for 2004 and from 0.83 ton $\mathrm{ha}^{-1} \mathrm{y}^{-1}$ to 350.16 ton $\mathrm{ha}^{-1} \mathrm{y}^{-1}$ for 2013 in the study area. For very low and low levels of wind erosion potential, the potential sediment yield varies from 0.83 ton $\mathrm{ha}^{-1} \mathrm{y}^{-1}$ to 4.52 ton $\mathrm{ha}^{-1} \mathrm{y}^{-1}$. For the medium level wind erosion potential class, the potential sediment yield varies from 6.74 ton $\mathrm{ha}^{-1} \mathrm{y}^{-1}$ to 15 ton $\mathrm{ha}^{-1} \mathrm{y}^{-1}$. Moreover, for the high and very high level wind erosion potential classes, the potential sediment yield varies from 21.29 ton $\mathrm{ha}^{-1} \mathrm{y}^{-1}$ to 350.16 ton $\mathrm{ha}^{-1} \mathrm{y}^{-1}$.

These results show that the area with a very high sediment yield potential increased, whereas the area with a low, medium, and high sediment yield potential decreased. The area with a very low sediment yield potential remained constant. $48.61 \%$ and $55.97 \%$ of the area include high and very high potential of wind erosion for 2004 and 2013, respectively.

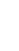


Table 10. Changes between wind erosion potential classes in 2004 and $2013(\%)$.

\begin{tabular}{|c|c|c|c|c|c|c|c|}
\hline & \multicolumn{6}{|c|}{2004} \\
\hline & & Very Low & Low & Medium & High & Very High & Total \\
\hline \multirow{6}{*}{$\stackrel{\text { }}{\stackrel{\sim}{\sim}}$} & Very Low & 100 & 0 & 0 & 0 & 0 & 100 \\
\hline & Low & 0 & 87.55 & 0 & 0 & 0 & 100 \\
\hline & Medium & 0 & 11.69 & 24.67 & 0 & 0 & 100 \\
\hline & High & 0 & 0.76 & 35.40 & 30.88 & 0 & 100 \\
\hline & Very High & 0 & 0 & 39.93 & 69.12 & 100 & 100 \\
\hline & Total & 100 & 100 & 100 & 100 & 100 & 100 \\
\hline
\end{tabular}

396

397

398

399

400

401

402

403

404

405

406

407

408

409

410

411

412

413

414

415

416

417

418

419

420

421

422

423

424

425

426

427

428

429

430
Comparing land use/cover changes and corresponding wind erosion potential changes in 2004 and 2013 indicated that soil wind erosion potential is mainly increasing due to the changes in land use/cover in this period, since the other factors remained constant. Many researchers found that land use/cover change affects soil erosion positively and negatively. Wijitkosum (2012), studied the impact of land use/cover change on soil erosion in Pa Deng Sub-district, Thailand. He found that soil erosion decreased when land use/cover changed from bare land in 1990 to forest in 2010. Yang et al. (2003) indicated that with development of cropland in the last century, global soil erosion potential is estimated to have increased by about 17\%. Moreover, Sharma et al. (2011) showed that transition of other land use/cover to cropland was the most detrimental to watershed in terms of soil loss.

Due to the low rainfall and high evapotranspiration, the study area has low vegetation cover and is susceptible to wind erosion even without human activities. However, according to the results obtained and field observations human activities including intensive livestock grazing, increasing cultivation, land use change from rangelands to agricultural lands, and from abandoned land to arable land and using the underground water supply resulted in increasing soil loss due to wind erosion.

Soil loss due to wind erosion from each land use/cover varies based on its characteristics like the vegetation cover type, surface roughness and management practices. The areas with an increase of soil erosion potential are located in the southern and northeastern parts of the study area. These areas mostly mainly exists of agricultural and rangeland. In these parts, extension of agricultural lands is obvious. The northern and northwestern parts showed no major change in sedimentation potential between 2004 and 2013. These parts includes areas that are not susceptible to wind erosion due the surface stoniness, hard soil surfaces (crust), which are not under cultivation. The central part (river basin), which is most of the time dry, shows a very high potential for wind erosion. The dry sediments inside the river basin are highly susceptible to wind erosion. In addition, lots of active Nebkas and sand sheets were found in the river basin that are ready to be transported by erosive wind.

The results indicated that the rangelands are susceptible to wind erosion. In total the area of rangeland decreased, and the potential for wind erosion in more than $90 \%$ rangelands increased to more than 60 ton $\mathrm{ha}^{-1} \mathrm{y}^{-1}$ (from high to very high) in 2013, whereas, agricultural lands increased in 2013 and they showed high (15-60 ton $\left.\mathrm{ha}^{-1} \mathrm{y}^{-1}\right)$ and very high (>60 ton ha-1 $\mathrm{y}^{-1}$ ) sedimentation potential. Sand sheets increased in 2013 in comparison to 2004 and their potential for wind erosion is mostly very high in both years. $94.97 \%$ of the sand sheets showed high and very high potential 
431 for wind erosion in 2013. For Nebkas, the sedimentation potential is also mostly very high and 432 they showed a decrease in area in $2013.63 .7 \%$ and $72.41 \%$ of the Nebkas have a sedimentation 433 potential of more than 60 ton ha ${ }^{-1} \mathrm{y}^{-1}$ in 2004 and 2013, respectively. 
Table 11. Cross-tabulation between land use/cover (in pixels numbers) and sedimentation potential in 2004.

\begin{tabular}{|c|c|c|c|c|c|c|c|c|c|c|c|c|c|c|}
\hline \multirow[b]{2}{*}{$\begin{array}{l}\text { Sedimentation } \\
\text { potential } \\
\left(\text { Ton } \mathbf{h a}^{-1} \mathbf{y}^{-1}\right)\end{array}$} & \multicolumn{13}{|c|}{ Land use/cover in 2004} & \multirow[b]{2}{*}{ Total } \\
\hline & Rangeland & $\begin{array}{c}\text { Sand } \\
\text { sheets }\end{array}$ & Nebka & $\begin{array}{c}\text { Agri. } \\
1\end{array}$ & $\begin{array}{c}\text { Agri. } \\
2\end{array}$ & Agri.3 & Agri.4 & $\begin{array}{l}\text { Bare } \\
\text { land }\end{array}$ & Ins.1 & Ins. 2 & Fan & Others & Unclassified & \\
\hline$<2.5$ & 135 & 189 & 570 & 230 & 402 & 214 & 473 & 1 & 5892 & 243 & 13699 & 4740 & 991 & 27779 \\
\hline $2.5-5$ & 649 & 968 & 893 & 241 & 371 & 413 & 2587 & 35 & 7928 & 4005 & 16909 & 13138 & 4418 & 52555 \\
\hline 5-15 & 356 & 841 & 1443 & 311 & 305 & 1227 & 4259 & 20 & 272 & 22 & 344 & 5779 & 2933 & 18112 \\
\hline $15-60$ & 11305 & 1447 & 1843 & 4995 & 5409 & 6786 & 14522 & 79 & 1164 & 182 & 1754 & 7756 & 7758 & 65000 \\
\hline$>60$ & 95 & 6045 & 5799 & 990 & 973 & 2684 & 1258 & 3745 & 118 & 39 & 32 & 6064 & 381 & 28223 \\
\hline Total & 12540 & 9490 & 10548 & 6767 & 7460 & 11324 & 23099 & 3880 & 15374 & 4491 & 32738 & 37477 & 16481 & 191669 \\
\hline
\end{tabular}

\section{0}

441

442

Table 12. Cross-tabulation between land use/cover (in pixels numbers) and sedimentation potential in 2013.

\begin{tabular}{|c|c|c|c|c|c|c|c|c|c|c|c|c|c|c|}
\hline \multirow[b]{2}{*}{$\begin{array}{l}\text { Sedimentation } \\
\text { potential } \\
\left(\text { Ton } \mathbf{h a}^{-1} \mathbf{y}^{-1}\right)\end{array}$} & \multicolumn{13}{|c|}{ Land use/cover in 2013} & \multirow[b]{2}{*}{ Total } \\
\hline & Rangeland & $\begin{array}{c}\text { Sand } \\
\text { sheets }\end{array}$ & Nebka & Agri.1 & $\begin{array}{l}\text { Agri. } \\
2\end{array}$ & Agri.3 & $\begin{array}{c}\text { Agri. } \\
4\end{array}$ & $\begin{array}{l}\text { Bare } \\
\text { land }\end{array}$ & Ins.1 & Ins. 2 & Fan & Others & Unclassified & \\
\hline$<2.5$ & 0 & 148 & 107 & 310 & 36 & 139 & 11 & 16 & 2782 & 621 & 9028 & 12239 & 2342 & 27779 \\
\hline $2.5-5$ & 0 & 114 & 233 & 441 & 130 & 805 & 416 & 49 & 1643 & 6592 & 11215 & 14909 & 9453 & 46000 \\
\hline $5-15$ & 0 & 466 & 491 & 600 & 69 & 424 & 66 & 35 & 104 & 2 & 373 & 3392 & 3840 & 9862 \\
\hline $15-60$ & 1 & 2994 & 716 & 3837 & 6802 & 1100 & 209 & 1283 & 246 & 677 & 163 & 3457 & 5403 & 26888 \\
\hline$>60$ & 3118 & 10762 & 4060 & 16734 & 1828 & 11364 & 3852 & 9271 & 9 & 2 & 237 & 5329 & 13878 & 80444 \\
\hline Total & 3119 & 14484 & 5607 & 21922 & 8865 & 13832 & 4554 & 10654 & 4784 & 7894 & 21016 & 39326 & 34916 & 190973 \\
\hline
\end{tabular}

443

444

445

446

447 
River tributary (and bare land) showed an increase in 2013 and its potential for being eroded by wind was very high in both years. $96.52 \%$ and $87.02 \%$ of the bare lands showed a sedimentation potential of more than 60 ton $\mathrm{ha}^{-1} \mathrm{y}^{-1}$ in 2004 and 2013, respectively. In general, seasonal rivers deposit their sediments in moist seasons with the sediments being transported by wind in dry seasons. These river beds are the most important eroding areas in Iran and most sand dunes have their source in river sediments in Iran (Ahmadi 1998).

More than 90 percent of the insusceptible areas and alluvial fans were found to have a very low and low sedimentation potential, due to their surface characterization discussed before.

It is obvious that with human activity like increasing agricultural lands, converting rangelands to cultivated lands, intensive grazing, and paying no attention to stabilizing sand dunes and Nebkas and climate factors including low rainfall, dry soil, and low vegetation coverage in the study area, soil wind erosion increased in the period between 2004 and 2013. These results indicate that policy and economic forces that shape land use decision making can have impact on wind erosion and, importantly, emission of dust with local and regional consequences.

\section{Conclusion}

Changes in land use/cover affect soil erosion considerably. These changes were especially increasing in agricultural lands and sandy areas. In order to reduce the potential of wind erosion, several practical works or guidelines can be considered:

- The seasonal river tributary which is one of the most important eroding areas in arid regions needs special attention from national and local governmental agencies for stabilizing shifting sands.

- Rangelands should be preserved from overgrazing and converting to low-income agricultural lands in order to decrease the unfavorable impact of cultivation practices on soil loss.

- To ensure a more efficient implementation of soil conservation in agricultural lands, a suitable agricultural practices must be applied. Perhaps, tillage ought to be limited to periods with low wind velocities to minimize soil loss by wind erosion

- Cropping pattern and a crop calendar must be applied to decrease the long fallow stage and consequently to increase the vegetation coverage of the soil surface.

\section{Acknowledgements}

The authors are grateful to the Natural Resources and Watershed Management Office of Fars province, Iran for providing thematic maps and technical advice. 


\section{References}

Ahmadi H. 1998. Applied Geomorphology (Desert-wind erosion). Tehran University Publication. 23:85-395.

Amiraslani F, Dragovich D. 2011. Combating desertification in Iran over the last 50 years: an overview of changing approaches. Journal of Environmental Management. 92(1):1-13.

Baret F, Guyot G, Major D. 1989. TSAVI: A vegetation index which minimize soil brightness effects on LAI and APAR estimation. 12 $12^{\text {th }}$ Canadian symposium on remote sensing and IGARSS'90; 1989; Vancouver Canada.

Baret F, Guyot G. 1991. Potentials and limits of vegetation indices of LAI and APAR assessment. Remote Sensing and the Environment. 35:161-173.

Bartholome E, Belward A.S. 2005. Glc2000: a new approach to global land cover mapping from Earth observation data. International Journal of Remote Sensing. 26(9):1959-1977.

Cebecauer T, Hofierka J. 2008. The consequences of land cover changes on soil erosion distribution in Slovakia. Geomorphology. 98:187-198.

Chavez Jr PS. 1988. An improved dark-object subtraction technique for atmospheric scattering correction for multispectral data. Remote Sensing of Environment. 24:459-479.

Cheng Y, Ustin SL, Riano D, Vanderbilt VC. 2008. Water content estimation from hyperspectral images and MODIS indexes in southern Arizona. Remote Sens Environ. 112:363374.

Clark R, MacEwan R, Robinson N, Hopley J. 2010. Remote sensing of land cover and land management practices affecting wind erosion risk in NW Victoria, Australia. $19^{\text {th }}$ World congress of soil science, soil solutions for a changing world; 2010 August 1-6; Australia.

Congalton RG, Green K. 1999. Assessing the accuracy of remotely sensed data, priciples and practices. CRC Press, Boca Raton, FL.

Dashtekian K, Pakparvar M, Abdollahi J. 2008. Study of soil salinity map preparing methods by using landsat images in Marvast. Iranian Journal of Range and Desert Research. 15:139-157.

Deering DW, Rouse JW, Haas RH, Schell JA. 1975. Measuring forage production of grazing units from Landsat MSS data. Proceedings of the $10^{\text {th }}$ international symposium on remote sensing of environment, II. 1169-1178.

Fister W, Ries JB. 2009. Wind erosion in the central Ebro Basin under changing land use management. Field experiments with a portable wind tunnel. Journal of Arid Environment. 73:9961004.

Garcia-Ruiz JM. 2010. The effects of land uses on soil erosion in Spain: A review. Catena. 81:111.

Gong P, Wang J, Yu L, Zhao Y, Zhao Y, Liang L, Niu Z, Huang X, Fu H, Liu S, Li C, Li X, Fu W, Liu C, Xu Y, Wang X, Cheng Q, Hu L, Yao W, Zhang H, Zhu P, Zhao Z, Zhang H, Zheng Y, Ji L, Zhang Y, Chen H, Yan A, Guo J, Yu L, Wang L, Liu X, Shi T, Zhu M, Chen Y, Yang G, Tang P, Xu B, Giri C, Clinton N, Zhu Z, Chen J, Chen J. 2013. Finer resolution observation and monitoring of global land cover: first mapping results with Landsat TM and ETM+ data. International Journal of Remote Sensing. 34(7):2607-2654.

Goossens D, Riksen M. 2004. Wind erosion and dust dynamics at the commencement of the $21^{\text {st }}$ century. In: D. Goossens and M. Riksen (Editors). Wind erosion and dust dynamics: observation, simulation, modelling. ESW publications; Wageningen. 7-13. 
531

532

533

534

535

536

537

538

539

540

541

542

543

544

545

546

547

548

549

550

551

552

553

554

555

556

557

558

559

560

561

562

563

564

565

566

567

568

569

570

571

572

573

574

Gumma MK, Thenkabail PS, Hideto F, Nelson A, Dheeravath V, Busia D, Rala A. 2011. Mapping irrigated areas of Ghana using fusion of $30 \mathrm{~m}$ and $250 \mathrm{~m}$ resolution remote-sensing data. Remote Sensing. 3:816-835.

Huete AR. 1988. A soil-adjusted vegetation index (SAVI). Remote Sensing and the Environment. 25:53-70.

Hui C, Jian L, Guizhou W, Guang Y, Lei L. 2015. Identification of sand and dust storm source areas in Iran. J Arid Land. 7(5):567-578.

Jia K, Wei X, Gu X, Yao Y, Xie X, Li B. 2015. Land cover classification using Landsat 8 operational land imager data in Beijing, China. Geocarto International. 29(8):941-951.

Jiang H. 2002. Culture, ecology and nature's changing balance: Sandification on Mu Us Sandy land, Inner Mongolia, China. In global desertification: Do humans cause deserts? Reynolds JF, Stafford Smith DM. Eds: Dahlem university press; 2002 Berlin, Germany. 181-196.

Karnieli A, Qin Z, Wu B, Panov N, Yan F. 2014. Spatio-temporal dynamics of land-use and land-cover in the Mu Us sandy land, China, using the change vector analysis technique. Remote Sens. 6:9316-9339

Khaier F. 2003. Soil salinity detection using satellite remote sensing, geo-information science and earth observation. International institute for geo-information science and earth observation: 170 .

Khan NM, Rastoskuev VV, Shalina E, Sato Y. 2001. Mapping salt-affected soil using remote sensing indicators. A simple approach with the use of GIS. IDRISI, 22 ${ }^{\text {nd }}$ Asian conference on remote sensing; 2001 November 5-9; Singapore.

Koutsias N, Pleniou M. 2015. Comparing the spectral signal of burned surfaces between Lndsat7 ETM+ AND Landsat 8 OLI sensors. International Journal of Remote Sensing. 36(14):3714-3732.

Laben CA, Brower BV. 2000. Process for enhancing the spatial resolution of multispectral imagery using pan-sharpening. Eastman Kodak Company, Tech. Rep. US Patent \#6,011,875.

Leh M, Bajwa S, Chaubey I. 2013. Impact of land use change on erosion risk: an integrated remote sensing, geographic information system and modeling methodology. Land Degradation and Development. 24:409-421.

Li J, Okin GS, Tatarko J, Webb NP, Herrick JF. 2014. Consistency of wind erosion assessments across land use and land cover types: A critical analysis. Aeolian Research. 15:253-260.

Liu J, Heiskanen J, Aynekulu E, Pellikka PKE. 2015. Seasonal variation of land cover classification accuracy of Landsat 8 images in Burkina Faso. The international archives of the photogrammetry, remote sensing and spatial information sciences. $36^{\text {th }}$ International symposium on remote sensing of environment, May 11-15 2015. Berlin, Germany.

Martinez-Casasnovas JA, Sanchez-Bosch I. 2000. Impact assessment of changes in land use/conservation practices on soil erosion in the Penedes-Anoia vineyard region (NE Spain). Soil \& Tillage Research 57:101-106.

Minwer Alkharabsheh M, Alexandridis TK, Bilas G, Misopolinos N, Silleos N. 2013. Impact of land cover change on soil erosion hazard in northern Jordan using remote sensing and GIS. Procedia Environmental Sciences. 19:912-92.

Mokhtari A, Ghayumiyan J, Feiznia S. 2005. Discrimination between lithology units using nonlinear correlation analysis of Landsat ETM data. $4^{\text {th }}$ Iranian conference of engineering geology and the environment; 2005; Iran. 
575

576

577

578

579

580

581

582

583

584

585

586

587

588

589

590

591

592

593

594

595

596

597

598

599

600

601

602

603

604

605

606

607

608

609

610
Natural Resources and Watershed Management Office (NRWMO) of Fars province, 2005. The studies of action plan of desert region management, Dowlatabad-Farashband region: Geology. 522.

Okin GS, Robert DA. 2004. Remote sensing in arid regions: challenges and opportunities, In: S.L. Ustin, (ED.). Remote sensing for natural resources management and environmental monitoring. Third ed. Hoboken, New Jersy. 111-145.

Perry CJr, Lautenschlager LF. 1984. Functional equivalence of spectral vegetation indecies. Remote Sensing and the Environment. 14:169-182.

Qi J, Chehbouni A, Huete AR, Kerr YH, Sorooshian S. 1994. A modified soil adjusted vegetation index. Remote Sensing and the Environment. 48:119-126.

Richards JA, Jia X. 2006. Remote sensing digital image analysis, an introduction. Berlin:Springer.

Richardson AJ, Wiegand CL. 1977. Distinguishing vegetation from soil background information. Photogrammetric Engineering and Remote Sensing. 43(12):1541-1552.

Rouse JWJr, Haas RH, Deering DW, Schell JA, Harlan JC. 1974. Monitoring the vernal advancement and retrogradation (green wave effect) of natural vegetation. Type III, final report. Greenbelt (MD): NASA/GSFC.

Sharma A, Tiwari KN, Bhadoria PBS. 2011. Effect of land use land cover change on soil erosion potential in an agricultural watershed. Environ Monit Assess. 173:789-801.

Szilassi P, Jordan G, van Rompaey A, Csillag G. 2006. Impact of historical land use changes on erosion and agricultural soil properties in Kali Basin at Lake Balaton, Hungary. Catena. 68:96108.

Thiam AK. 1997. Geographic information systems and remote sensing methods for assessing and monitoring land degradation in the Sabel: The case of southern Mauritania. Doctoral dissertation, Clark University, Worcester Massachusetts.

Webb NP, Strong CL. 2011. Soil erodibility dynamics and its representation for wind erosion and dust emission models. Aeolian Res. 3(2):165-179.

Wijitkosum S. 2012. Impact of land use changes on soil erosion in Pa Deng Sub-district, Adjucent area of Kaeng Krachan national park, Thailand. Soil \& Water Resources. 7(1):10-17.

Yang D, Kanae S, Oki T, Koike T, Musiake K. 2003. Global potential soil erosion with reference to land use and climate changes. Hydrological Processes. 17:2913-2928.

Yousefi S, Mirzaee S, Tazeh M, Pourghasemi H, Karimi H. 2015. Comparison of different algorithms for land use mapping in dry climate using satellite images: a case study of the central regions of Iran. Desert. 20(1):1-10.

Yue Y, Shi P, Zou X, Ye X, Zhu Ax, Wang Ja. 2015. The measurement of wind erosion through field survey and remote sensing: a case study of Mu Us desert, China. Nat Hazards. 76:1497-1514. 